УДК 691.32.001.4

DOI https://doi.org/10.32782/2664-0406.2020.37.3

\title{
Дмитриева Н.В.
}

к.т.н., доцент,

Одесская государственная академия строительства и архитектуры, г. Одесса

\section{Трофимова Л.Е.}

к.т.н., доцент,

Одесская государственная академия строительства и архитектуры, г. Одесса

\section{Кирилюк С.В.}

к.т.н., заведующий лаборатории,

Одесская государственная академия строительства и архитектуры, г. Одесса

\section{Шамшур А.П.}

преподаватель, заведующий лаборатории,

Бендерский политехнический филиал

Приднестровского государственного университета имени Т.Г. Шевченко, Молдова

\section{ПОВЫШЕНИЕ ЭФФЕКТИВНОСТИ ГИДРОИЗОЛЯЦИОННЫХ ЭКРАНОВ В РАМКАХ КОНЦЕПЦИИ СОХРАНЕНИЯ ОБЪЕКТОВ КУЛЬТУРНОГО НАСЛЕДИЯ}

\begin{abstract}
Анотація. У статті розглянуті причини порушення гідроізоляції підземних частин будівель із вапняку-черепашнику. Розкриваються проблеми збереження історичних будівель і споруд із вапняку-черепашнику в Україні та Молдові, таки як Одеський театр опери та балету, Будинок Страча, Бродська синагога, Дім Маразлі, Білгород-Дністровська та Бендерська фортещі, Башта Вітрів, Костел святого Каетана, Порохової льох фортещі Тирасполь, Водяний Млин, Церква Архангела Михаїла в с. Строенщи і багато інших.

Обгрунтовано дощільність проведення досліджень ефективності ін'єкційної технології в процесі влаштування гідроізолячійних екранів в залежності від таких факторів: глибина ін'єктування (X1); діаметр шпуру (Х2); крок ін'єктування (Х3) при діапазоні варіювання $X 1$ - 14, 16 i $18 \mathrm{~cm}, X 2-8,12$ i $16 \mathrm{~mm}, X 3-10,15$ i $20 \mathrm{~cm}$

На основі методів математичної теорї експерименту побудований комплекс експериментально-статистичних моделей, аналіз яких дав змогу оцінити інтенсивність капілярного всмоктування системи «гідроізолячійний екран - вапняк-черепашник» залежно від глибини ін'єктування, діаметру ін'єктора і кроку його розташування.

Запропоновано і обгрунтовано схему розташування шпурів ін'єктування для забезпечення гідроізоляції конструкцій, яка дає змогу на 6-12\% більше заповняти капілярно-пористого простору кладки в порівнянні з іншими схемами.

Прийнята фізична модель поширення ін'єкційного складу в пористій структурі вапняку-черепашнику дозволила проаналізувати глибину, діаметр, крок ін'єктування, які впливають на область поширення розчину в масиві конструкиї. Глибина ін'єктування дійсно є однією з найважливіших технологічних характеристик у процесі влаштування внутрішньоконструкціонного гідроізоляиійного екрана. 3 технологічної точки зору ступінь впливу кроку ін'єктування на інтенсивність капілярного влагопереноса є досить високою, бо прямим чином позначається на кількості діючого гідроізолячійного складу в товщі, яка ін'єктується, а також на трудовитрати при виконанні гідроізолящійних робіт. Величина діаметра шпуру не робить значного впливу на досліджуваний показник у рамках вибраних умов експерименту.

Ключові слова: вапняк-черепашник, ін'єкційна гідроізоляція, гідроізоляційний екран, капілярний ефект, математичне моделювання.
\end{abstract}


Постановка проблемы. В настоящее время наблюдается тенденция к возрождению у населения активного интереса к истории своего края. Реконструкция исторической застройки стала социально значимой. В связи с этим остро стоит проблема сохранения исторических зданий и сооружений, неудовлетворительное состояние которых требует мероприятий по спасению их от повреждений, о которых наглядно свидетельствуют многочисленные трещины, обрушившиеся конструкции, а то и вовсе разрушения уникальных сооружений.

Как свидетельствуют данные обследований зданий и сооружений, в южном регионе Украины и Молдовы наиболее остро наблюдается снижение эксплуатационной надежности подземных частей объектов, то есть объектов с нарушенной или вышедшей из строя вертикальной и горизонтальной гидроизоляцией, находящейся в грунтовой среде.

Зачастую отечественные строительные фирмы без должного критического анализа используют импортные материалы и технологии, не предназначенные для определенных гидрогеологических условий. В результате после выполненных гидроизоляционных работ состояние здания или сооружения не улучшается.

При выборе типа гидроизоляции необходимо определить его соответствие предъявляемым требованиям с учетом специфики и состояния конкретного объекта, гидрогеологических условий, глубины заложения подземных конструкций, влияния изменения окружающей среды, и только после этого определить состав принятой гидроизоляции (количество слоев, толщину) [3].

Методы гидроизоляции старинных построек должны удовлетворять требованиям как к их конструкционной сохранности, так и к сохранению внешнего облика [4]. Поэтому исследования, посвященные поиску оптимальных технологических решений устройства гидроизоляционных экранов зданий из известняка-ракушечника, являются актуальными.

Анализ последних исследований. Основная часть зданий и сооружений в южном регионе Украины и Молдовы была возведена из известняка-ракушечника, который на протяжении многих лет является местным строительным материалом.

Среди множества зданий и сооружений, построенных из пильного известняка, есть и объекты культурного наследия: Одесский театр оперы и балета, Дом Страца, Бродская синагога, Дом Маразли (рис. 3), Белгород-Днестровская и Бендерская крепости (рис. 4, 5), Башня Ветров, Костел святого Каэтана (рис. 2), Пороховой погреб крепости Тирасполь, Водяная Мельница (рис. 1), Церковь Архангела Михаила в с. Строенцы и многие другие.

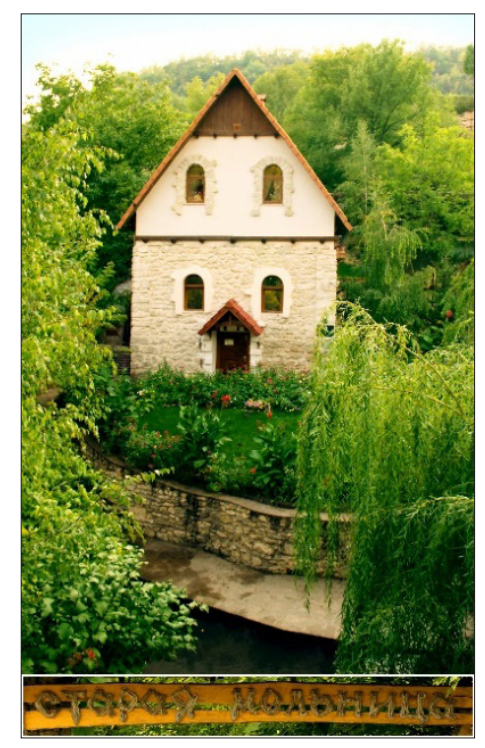

Рис. 1. Водяная Мельница с. Строенцы, Молдова

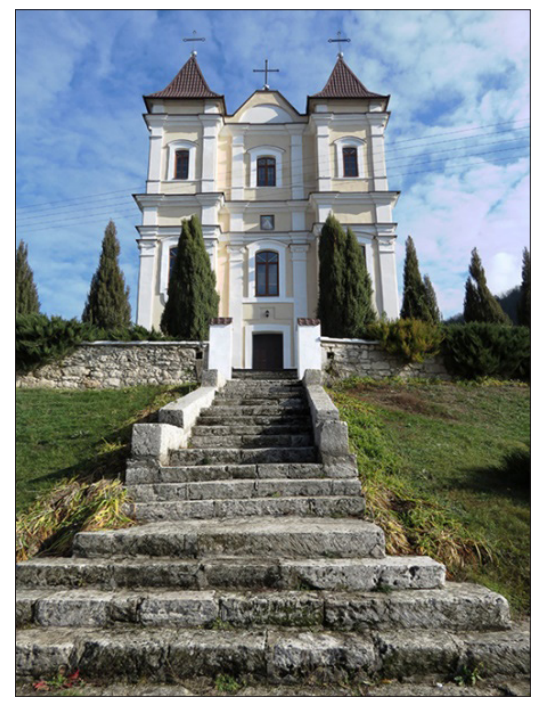

Рис. 2. Костел святого Каэтана с. Рашков, Молдова

Кладка подземных частей зданий из известняка-ракушечника подвергается воздействию деструктивных процессов, связанных с фильтрацией подземных вод, выщелачиванием, что постепенно приводит к утрате структурной целостности и ухудшению физико-механических свойств конструкции. 
В результате наступает физический износ этих конструкции, проявляющийся в образовании трещин, пустот, провалов, что нередко влечет к обрушению отдельных частей сооружения или сооружения в целом.

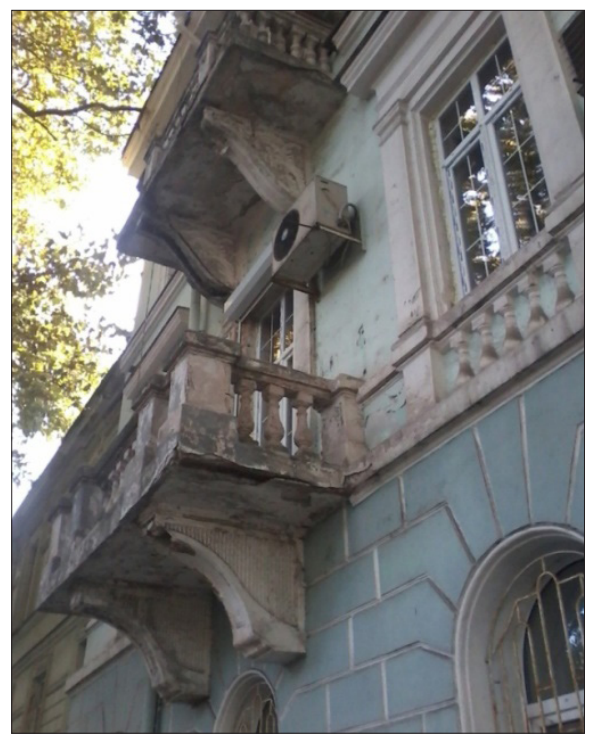

Рис. 3. Дом Маразли, ул. Пушкинская, 4, Одесса

Также причиной непродолжительного срока службы гидроизоляции могут стать: низкое качество гидроизоляционных материалов, большое число ручных операций, несовершенство и недостаток средств механизации.

В последние годы все более нарастающими темпами проводятся исследования по совершенствованию технологии и механизации гидроизоляционных работ, разработке новых технологических процессов, созданию новых материалов, применение которых позволило бы получать качественную гидроизоляцию с высокой эксплуатационной эффективностью.

Вопросами изучения физико-механических свойств камня известняка ракушечника занимались А.В. Комышев, П.Л. Еременок, Ю.В. Измайлов, А.Г. Фигаров, Ф.М. Оруджев, Н.Т. Турсунов, С.Н. Щербина [1-3] и др.

Вопросам защиты конструкций подземной части зданий и устройства гидроизоляции посвящены труды С.Н. Алексеева, В.О. Афанасьева, В.И. Бабушкина, В.В. Бойко, Ю.М. Баженова, Д.Ф. Гончаренко, А.А. Шилина, О.А. Лукинского, В.П. Хоменко, С.Н. Леоновича, Е.К. Карапузова, В.Г. Соха, А.И. Менейлюка, Н.В. Дмитриевой и др.

Цель работы. В связи с вышеизложенным целесообразно проведение исследования эффективности инъекционной технологии при устройстве гидроизоляционных экранов в зависимости от следующих факторов: глубина инъектирования $\left(\mathrm{X}_{1}\right)$; диаметр шпура $\left(\mathrm{X}_{2}\right)$; шаг инъектирования $\left(\mathrm{X}_{3}\right)$.

Результаты исследований. Глубина инъектирования - 14, 16 и 18 см. Диаметры используемых шпуров - 8, 12 и 16 мм. Шаг инъектирования - 10, 15 и 20 см (рис. 6).

Эксперимент проводился с использованием образцов известняка-ракушечника Григориопольского карьера (Молдова) марки M35. Макроструктура образца приведена на рис. 7. Определялось изменение величины капиллярного влагопереноса для образцов, подвергавшихся инъектированию гидроизоляционным составом SiltekVP-35. Высота

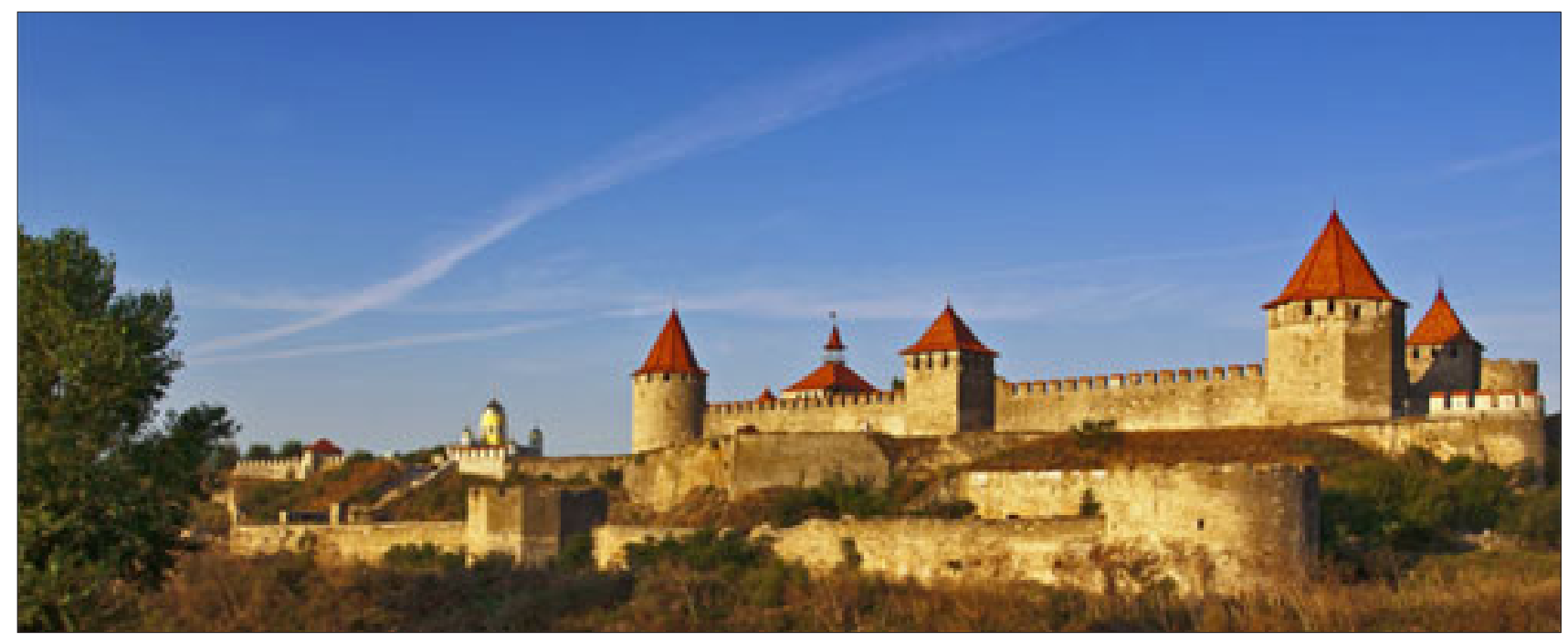

Рис. 4. Бендерская крепость (Молдова) 
подъема жидкости при капиллярном всасывании - 5, 10 и 15 мм.

Эксперименты по определению критерия качества материала (капиллярного подсоса) проводились по трехуровневому 15-точечному трехфакторному плану типа В3. Расчет коэффициентов и регрессионный анализ моделей типа (1) проводились по системе COMPEX [5]

$$
\begin{gathered}
\hat{Y}=b_{0}+b_{1} x_{1}+b_{11} x_{1}^{2}+b_{12} x_{1} x_{2}+b_{13} x_{1} x_{3} \\
+b_{2} x_{2}+b_{22} x_{2}^{2}+b_{23} x_{2} x_{3} \\
+b_{3} x_{3}+b_{33} x_{3}^{2}
\end{gathered}
$$

Переход от натуральных переменных к кодированным осуществлен по стандартной методике (2):

$$
\begin{gathered}
x_{i}=\left(X_{i}-X_{0 i}\right) / \Delta X_{i}, \text { где } X_{0 i}=0,5\left(X_{\text {imax }}+X_{\text {imin }}\right) \\
\Delta X_{i}=0,5\left(X_{\text {imax }}-X_{\text {imin }}\right)
\end{gathered}
$$

По результатам расчета в программном комплексе COMPEX были получены следующие экспериментально-статистические модели (3-5) капиллярного переноса жидкости при высоте подъема жидкости 5, 10 и 15 мм:

$$
\begin{gathered}
\hat{Y}_{1}=99,24-10,80 x_{1}-27,56 x_{1}^{2}+17,44 x_{2}^{2}, \\
-14,30 x_{3}+7,94 x_{3}^{2} ; \\
\hat{Y}_{2}=130,47-16,70 x_{1}-28,83 x_{1}^{2}+5,13 \\
x_{1} x_{2}+22,67 x_{2}^{2}+3,88 x_{2} x_{3}, \\
-20,40 x_{3}+8,67 x_{3}^{2} ; \\
\hat{Y}_{3}=151,82-9,00 x_{1}-18,78 x_{1}^{2}+ \\
6,50 x_{1} x_{2}+3,60 x_{2}+16,22 x_{2}^{2}, \\
-21,80 x_{3}+11,22 x_{3}^{2} .
\end{gathered}
$$

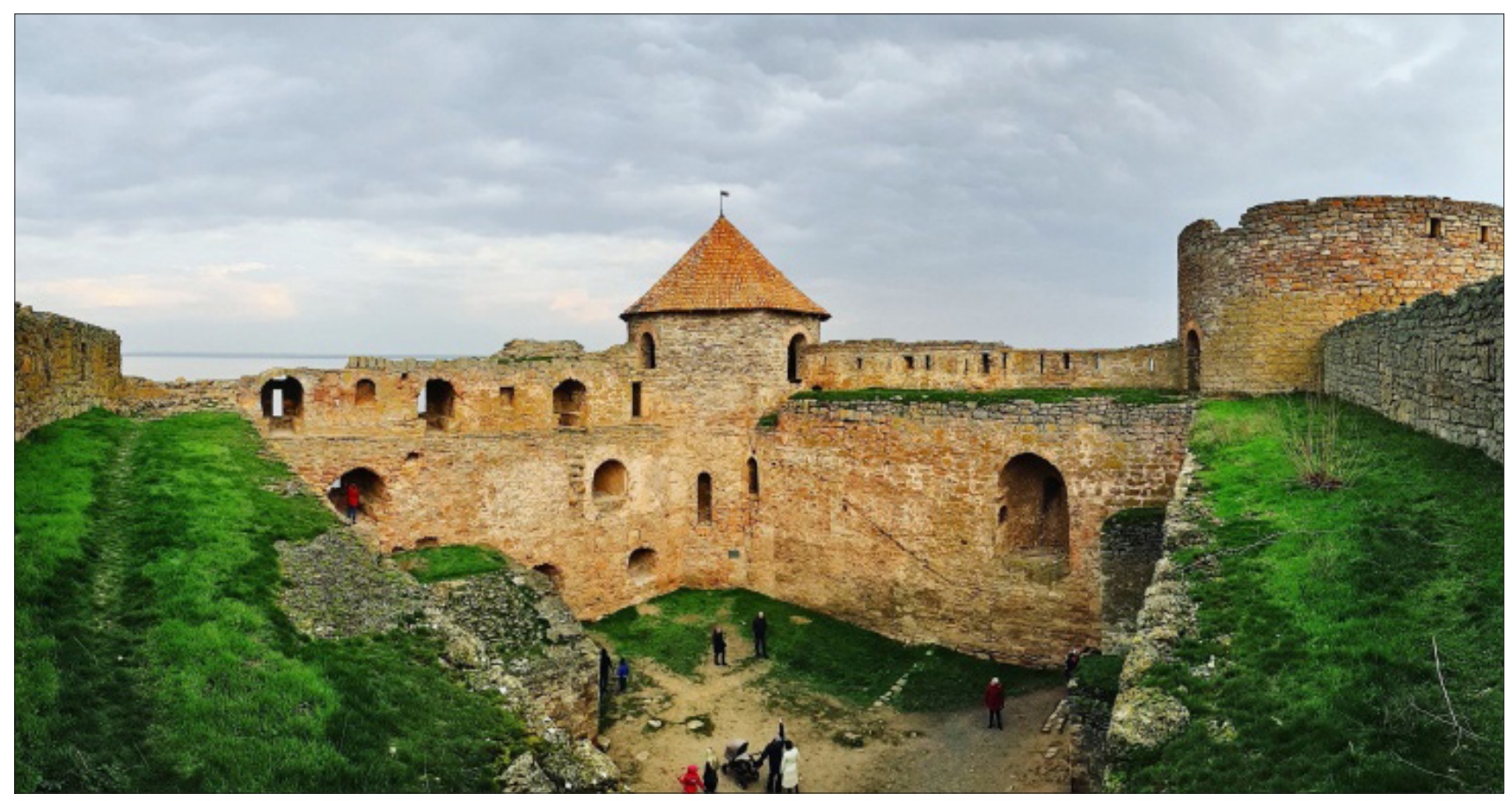

Рис. 6. Схема расположения инъектора диаметром 16 мм с шагом 10 см

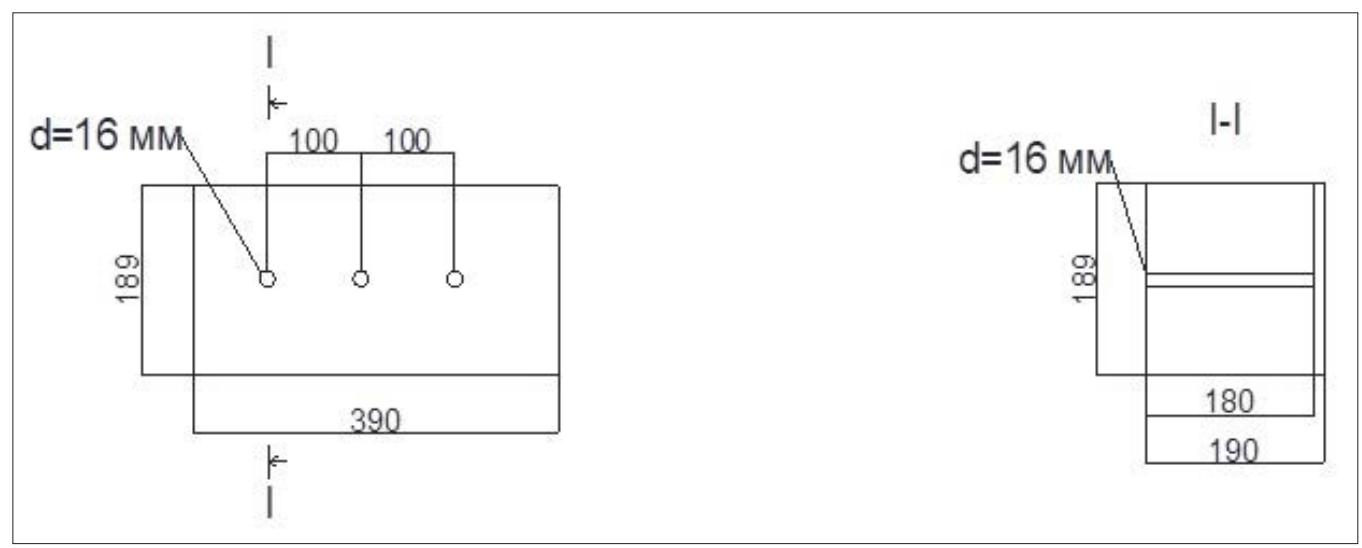

Рис. 7. Структура образцов Григориопольского карьера 
Анализ графиков ранжирования на рис. 8 показал, что степени влияния варьируемых факторов на показатель интенсивности капиллярного переноса влаги (высота подъема жидкости 5 мм) одинаковы в зонах максимума и минимума при одинаковом характере ранжирования. Наиболее значительным является фактор глубины инъектирова- ния. Большое влияние оказывает величина шага инъектирования. При этом величина диаметра шпура существенного влияния на интенсивность капиллярного влагопереноса не оказывает.

При рассмотрении ранжирования степени влияния варьируемых факторов на показатель интенсивности капиллярного переноса

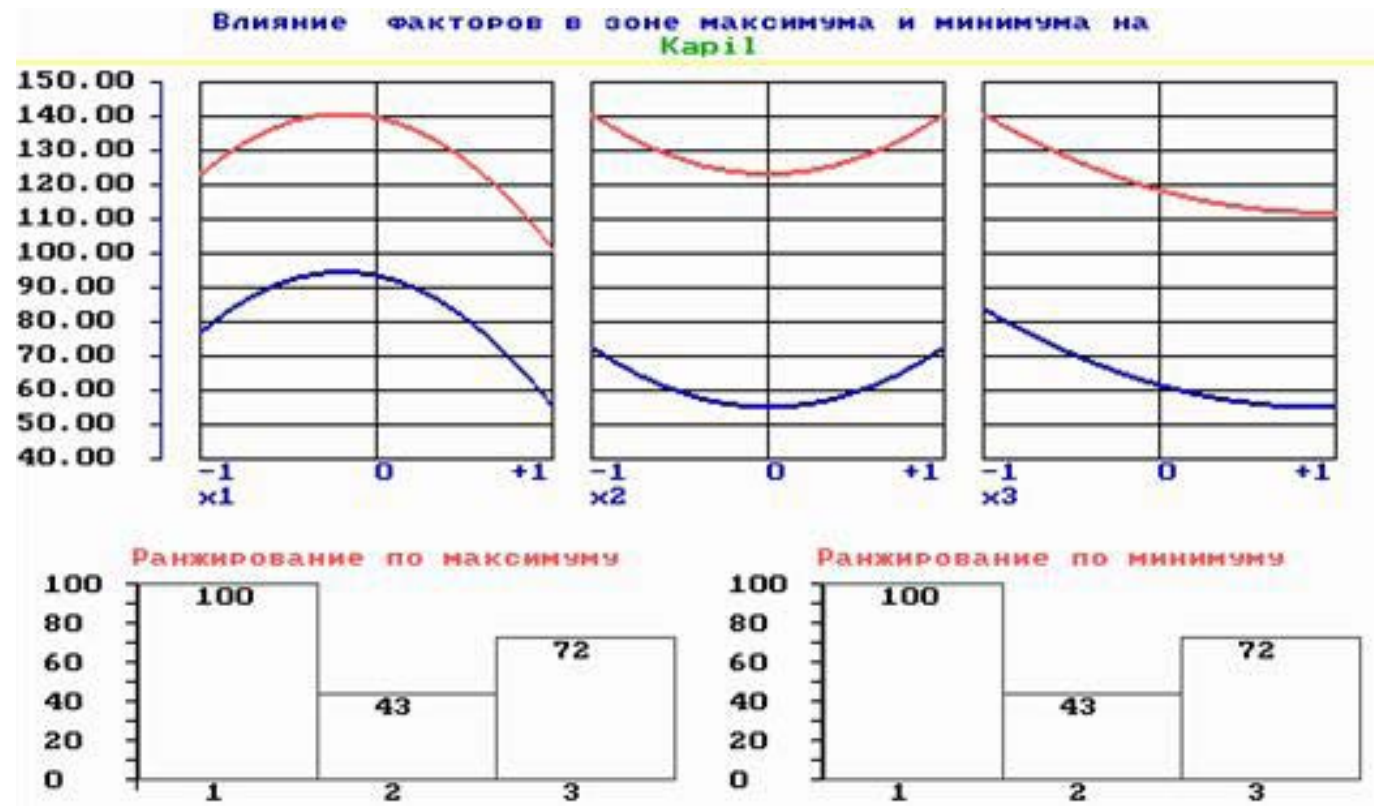

Рис. 8. Ранжирование влияния варьируемых факторов на показатель интенсивности капиллярного влагопереноса при высоте подъема жидкости 5 мм

DOSBox 0.63,Cpu Cycles: 30000, Frameskip 0, Program: FAKMIMAX $-$
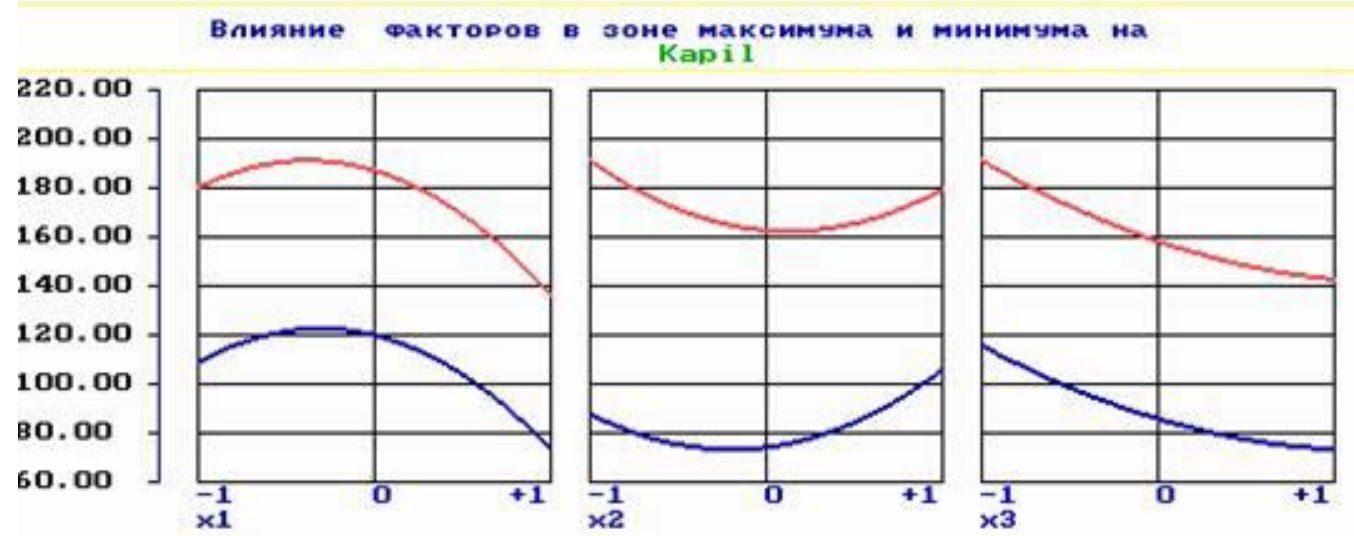

Ранжирование по макоимчмy
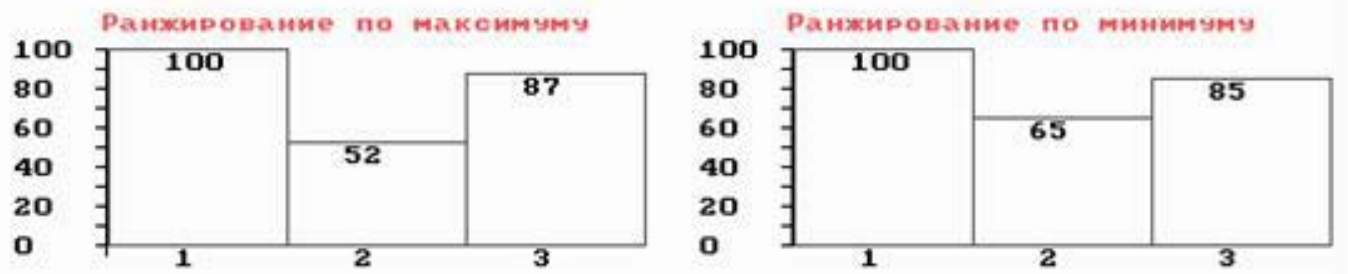

Рис. 9. Ранжирование влияния варьируемых факторов на показатель интенсивности капиллярного влагопереноса при высоте подъема жидкости 10 мм 
влаги при высоте подъема жидкости 10 мм (время 5 мин) выясняется, что степени влияния факторов в зоне экстремумов различны, хотя характер их ранжирования одинаков (рис. 9).

В зоне максимума наибольшее влияние на интенсивность капиллярного влагопереноса оказывают два фактора: глубина инъектирования (в большей степени) и шаг инъектирования. Диаметр инъектирования незначительно влияет на изменение показателя интенсивности. В зоне минимума влияние глубины инъектирования также является наиболее значимым; при этом степень влияния шага инъектирования немного снизилась. Степень значимости диаметра шпура в данном факторном пространстве несколько увеличилась.

Как видно из рис. 10, при высоте подъема жидкости 15 мм (время 5 мин) наибольшее влияние на показатель интенсивности капиллярного переноса влаги в зоне максимума оказывает шаг инъектирования. При этом степень влияния глубины инъектирования и диаметра шпура находятся примерно на одном уровне (достаточно низком). В зоне минимума влияние шага инъектирования также является наиболее значительным. Степень влияния глубины инъектирования и диаметра шпура повысилась.
Таким образом, анализ графиков на рис. 8-10 показал, что наибольшее влияние на интенсивность капиллярного влагопереноса в рамках выбранного факторного пространства оказывают глубина и шаг инъектирования; при этом значимость шага иньектирования увеличивается по мере роста высоты подьема жидкости. Диаметр шпура не оказывает значительного влияния на исследуемый показатель во всем диапазоне изменения высоты подъема жидкости.

Как известно, влияние каждого из факторов на расчетное значение выхода системы $\hat{Y}$ описывается параболой. Однако в своем влиянии на показатель качества $\hat{Y}$ фактор $x_{i}$ не независим, а взаимодействует с другими факторами $x_{j}$, что находит количественную оценку в эффектах модели типа $b_{i j} x_{i} x_{j}$. Поэтому анализ влияния факторов следует вести по квазиоднофакторным моделям вида:

$$
\hat{\mathrm{W}}_{\mathrm{i}}=\hat{\mathrm{Y}}\left\{\mathrm{x}_{\mathrm{j}}\right\}-\mathrm{b}_{0 \mathrm{j}}=\left(\mathrm{b}_{\mathrm{i}}+\mathrm{b}_{\mathrm{ij}} \mathrm{x}_{\mathrm{j}}\right) \mathrm{x}_{\mathrm{i}}+\mathrm{b}_{\mathrm{ii}} \mathrm{x}_{\mathrm{i}}^{2},
$$

где $b_{0 j}$ - свободный член, отражающий влияние на выход всех членов полинома, кроме включенных в модель (6). Таким образом, для модели типа (1) в общем случае могут быть получены по три квазиоднофакторные модели типа (6).

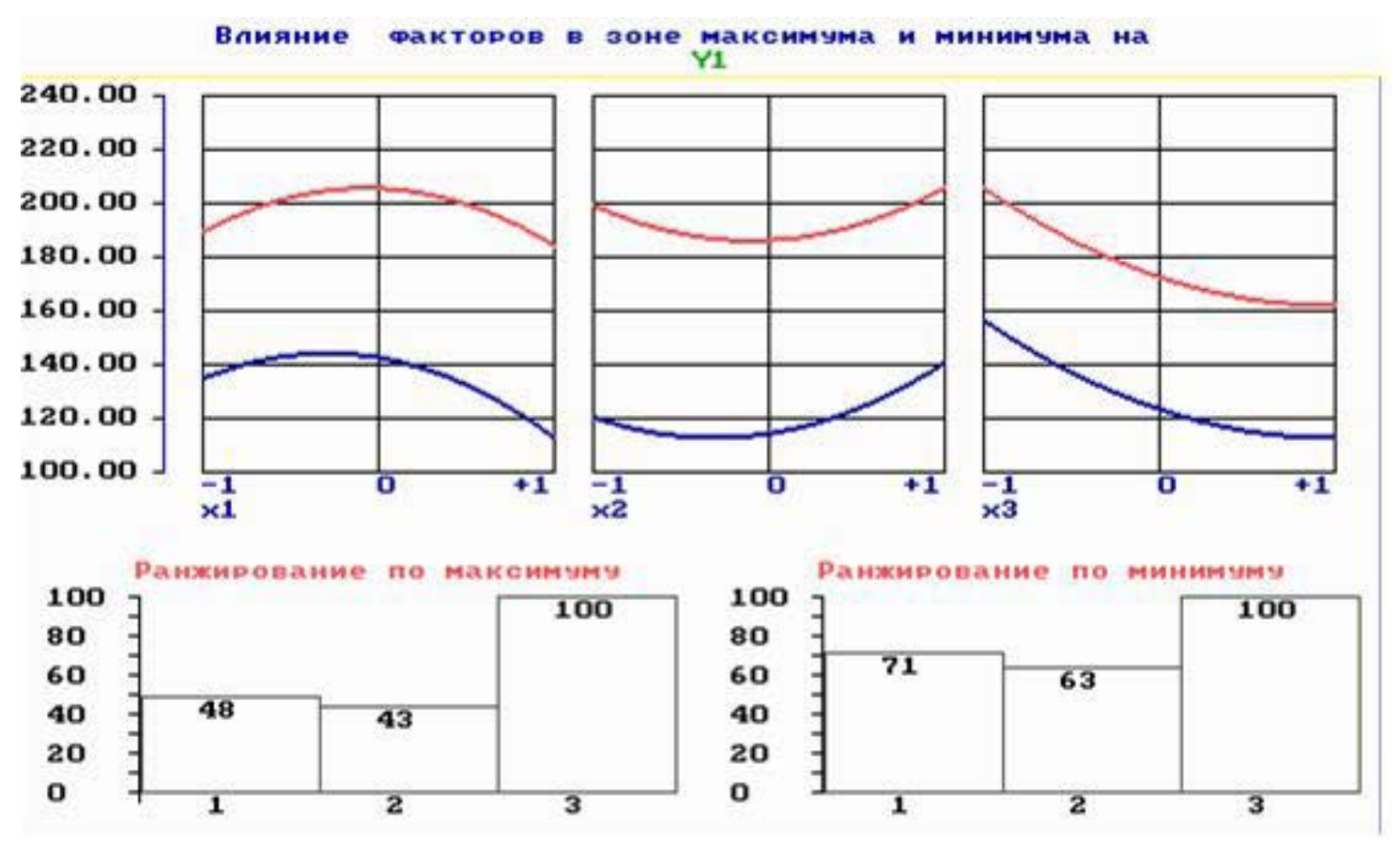

Рис. 10. Ранжирование влияния варьируемых факторов на показатель интенсивности капиллярного влагопереноса при высоте подъема жидкости 15 мм 
Следует отметить, что в модели интенсивности капиллярного переноса жидкости при высоте подъема жидкости 5 мм (3) эффекты взаимодействия отсутствуют.

Для модели (4) получено три квазиоднофакторные модели типа (7-9):

$$
\begin{gathered}
\hat{\mathrm{W}}_{3 / 1}=\left(-16,70+5,13 \mathrm{x}_{2}\right) \mathrm{x}_{1}-28,83 \mathrm{x}_{1}^{2} \\
\hat{\mathrm{W}}_{3 / 2}=\left(+5,13 \mathrm{x}_{1}+3,88 \mathrm{x}_{3}\right) \mathrm{x}_{2}+22,67 \mathrm{x}_{2}^{2} \\
\hat{\mathrm{W}}_{3 / 3}=\left(-20,40+3,88 \mathrm{x}_{2}\right) \mathrm{x}_{3}+8,67 \mathrm{x}_{3}^{2}
\end{gathered}
$$

Из анализа моделей (7-9) получены важные результаты. Эффекты взаимодействия $b_{i j}$ меняют значение линейного эффекта $b_{i}$. Поскольку каждый фактор исследуется в пределах от -1 до +1 , то их подстановка в модели (7-9) приводит от единичной параболы к семейству парабол (10-12):

$$
\begin{gathered}
\hat{W}_{3 / 1}=(-16,70 \pm 5,13) x_{1}- \\
28,83 x_{1}^{2}, \quad-21,83 \leq b_{x 1} \leq-11,57, \\
\hat{W}_{3 / 2}=( \pm 9,01) x_{2}+22,67 x_{2}^{2}, \\
-9,01 \leq b_{x 2} \leq+9,01, \\
\hat{W}_{3 / 3}=(-20,40 \pm 3,88) \\
x_{3}+8,67 x_{3}^{2}, \quad-24,28 \leq b_{x 3} \leq-16,52,
\end{gathered}
$$

Такие семейства парабол изображены на рис. 11, на котором нанесены центральная и две граничные параболы, а зона существо- вания семейств заштрихована. Эффекты взаимодействия передвигают вершину неизменной параболы вдоль оси $x_{i}$.

Анализ квазиоднофакторных моделей на рис. 11 дал возможность сделать выводы о роли каждого фактора с учетом эффектов взаимодействия.

Переход к большей глубине шпура вначале приводит к увеличению $Y$, затем этот эффект понижается. Положение фактора $x_{1}$ соответствующее максимальному значению выхода, определяется уровнем стабилизации других факторов.

Увеличение диаметра шпура до 12 мм вызывает уменьшение $Y$; дальнейшее увеличение диаметра приводит к росту $Y$.

Увеличение шага инъектирования приводит к уменьшению во всем диапазоне изменения $X_{3}$.

Для модели (5) также получены три квазиоднофакторные модели, представленные на рис. 12. Следует отметить, что характер влияния факторов на $Y$ со временем не изменился.

Анализ показал, что максимальное значение $Y$ во всех трех случаях обеспечивается одинаковыми уровнями факторов: незначительная глубина шпура, максимальный диаметр шпура, минимальный шаг инъектирования, что соответствует глубине

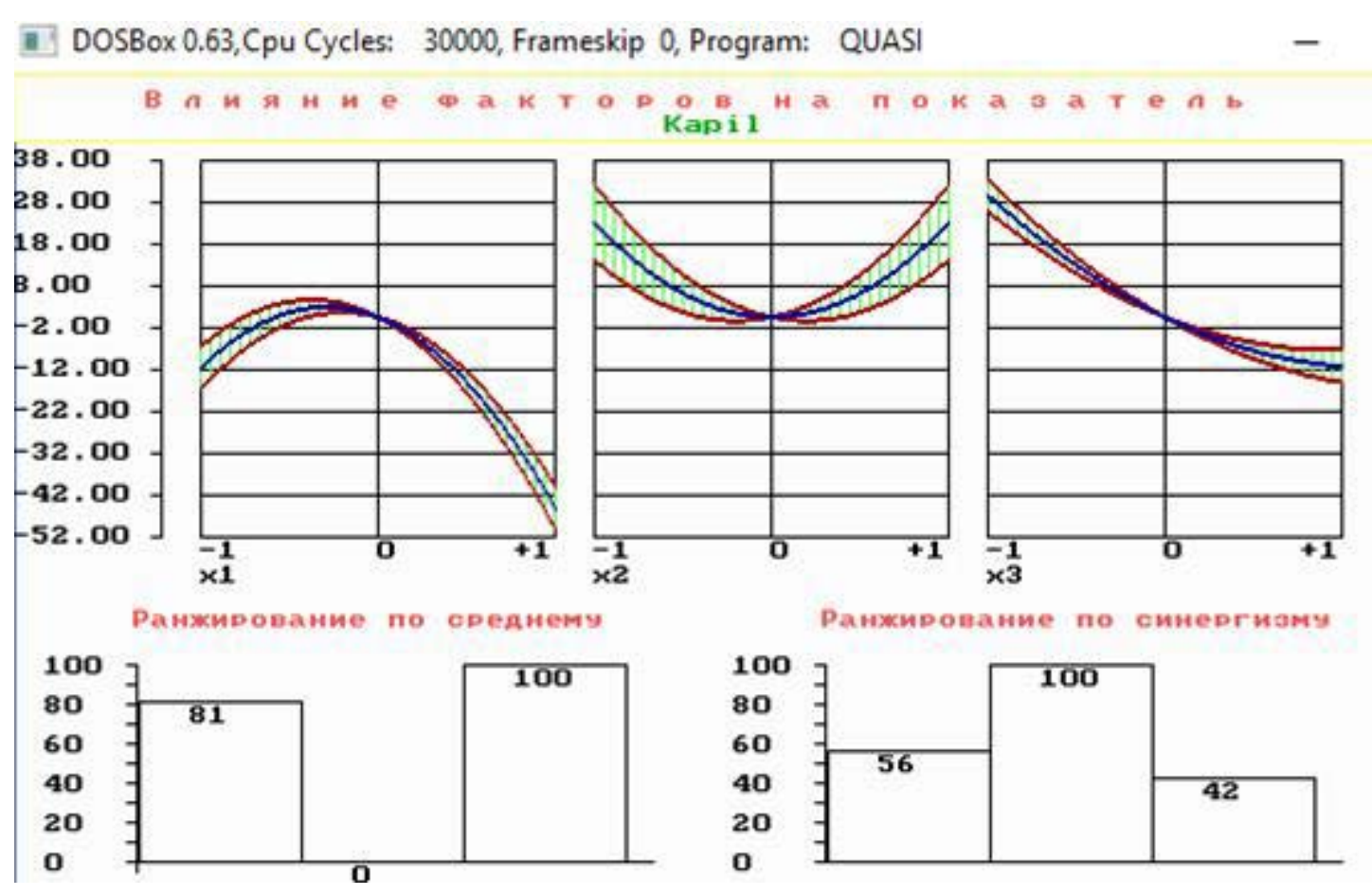

Рис. 11. График влияния факторов на показатель интенсивности капиллярного влагопереноса при высоте подъема жидкости 10 мм 


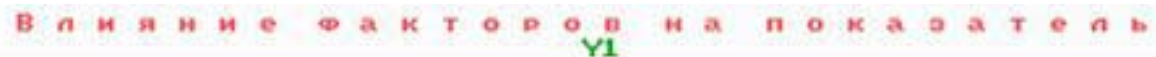

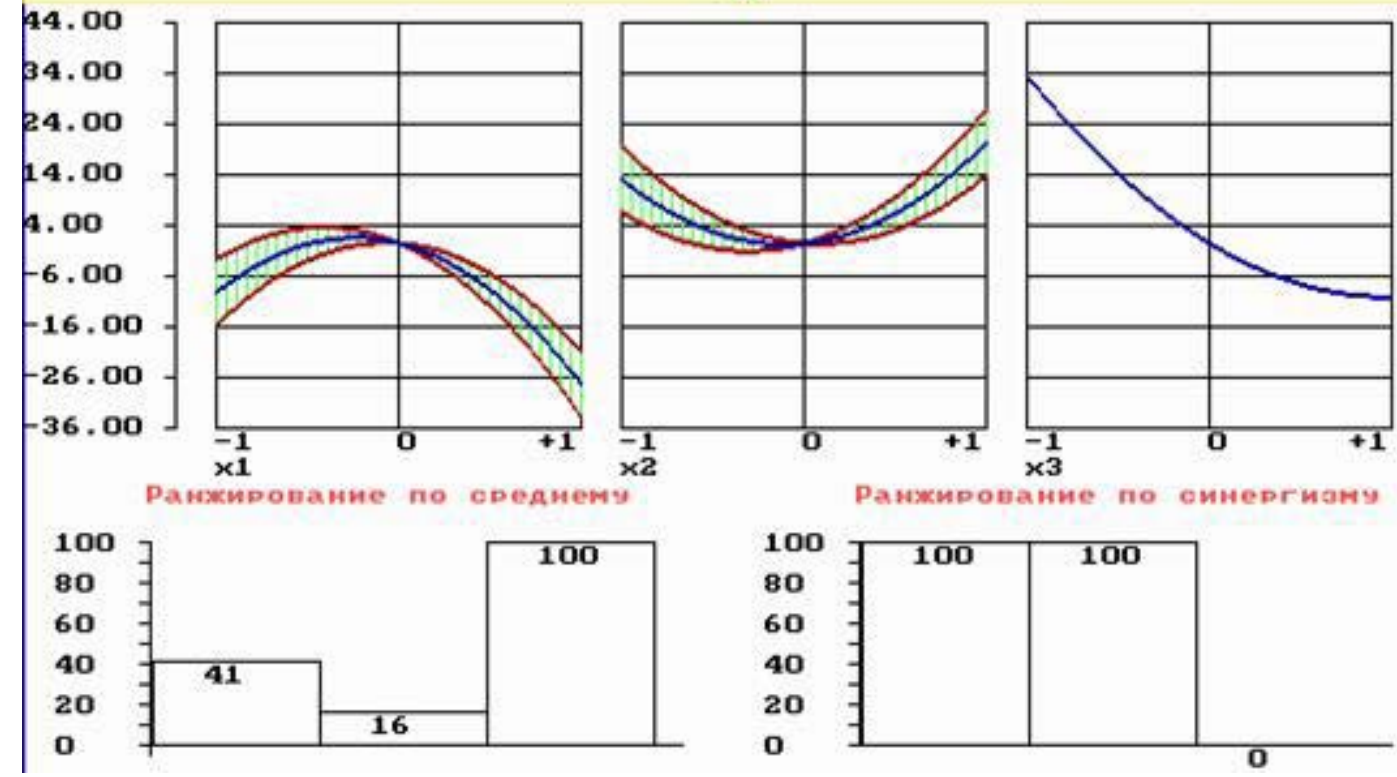

Рис. 12. График влияния факторов на показатель интенсивности капиллярного влагопереноса при высоте подъема жидкости 15 мм

инъектирования 14 см, диаметр шпура 8 мм, шаг инъектирования $15 \mathrm{~cm}$.

Минимальное значение $Y$ на протяжении всего эксперимента обеспечивается максимальной глубиной шпура при значительном шаге инъектирования, что соответствует глубине инъектирования 18 см, шагу инъектирования 20 см. При этом диаметр шпура не превышает 12 мм.

Выводы. Предложена и обоснована схема расположения шпуров инъецирования для обеспечения гидроизоляции конструкций, которая позволяет на 6-12\% больше заполнить капиллярно-пористого пространства кладки по сравнению с другими схемами.

Принятая физическая модель распространения инъекционного состава в пористой структуре известняка-ракушечника позволи- ла проанализировать глубину, диаметр, шаг инъецирования, которые оказывают влияние на область распространения раствора в массиве конструкции. Глубина инъектирования действительно является одной из важнейших технологических характеристик при устройстве внутриконструкционного гидроизоляционного экрана. C технологической точки зрения степень влияния шага инъектирования на интенсивность капиллярного влагопереноса является достаточно высокой, так как прямым образом сказывается на количестве действующего гидроизоляционного состава в инъецируемой толще, а также на трудозатратах при выполнении гидроизоляционных работ. Величина диаметра шпура не оказывает значительного влияния на исследуемый показатель в рамках выбранных условий эксперимента.

\section{Jumepamypa}

1. Зарубина Л.П. Гидроизоляция конструкций, зданий и сооружений. Санкт-Петербург : БХВ-Петербург, 2011. $54 \mathrm{c}$.

2. Поляков С.В. Каменная кладка из пильных известняков / Поляков С.В., Измайлов Ю.В., Коноводченко В.И., Оруджев Ф.М., Поляков Н.Д. Кишинев, 1973.

3. Щербина С.Н. Влияние капиллярного всасывания влаги и её испарения на влагосодержание стен зданий / Щербина С.Н., Броник О.Н., Стерник Т.Н., Данченко Г.А. Вісник ОДАБА. 2008. № 32.

4. Дмитриева Н.В Анализ инновационных методов восстановления гидроизоляции конструкций из известняка-ракушечника / Дмитриева Н.В., Гострик А.О. Вісник ОДАБА. 2015. № 62. С. 111-116.

5. Вознесенский В.А. ЭВМ и оптимизация композиционных материалов / Вознесенский В.А., Ляшенко Т.В., Иванов Я.П., Николов И.И. Киев : Будівельник, 1989. 240 с. 


\title{
References
}

1. Zarubina L.P. (2011). Hidroizoliatsiia konstruktsii, zdanii and sooruzhenii. St. Petersburg: BKhV- Petersburg. 54 p. 2. Poliakov S.V., Izmailov Yu. V., Konovodchenko V.I., Orudzhev F.M. and Poliakov N.D. (1973). Kamennaia kladka iz pilnykh izvestniakov. Kichynev.

3. Shcherbina S.N., Bronik O.N., Sternik T.N. and Danchenko G.A. (2008). Vliianie kapilliarnogo vsasyvaniia vlagi i ee ispareniia na vlagosoderzhanie sten zdanii. Visnyk ODABA. No. 32.

4. Dmitrieva N.V. and Hostrik A.O. (2015). Analiz innovatsionnykh metodov vosstanovleniia hidroizoliatsii konstruktsii iz izvestniaka-rakushechnika. Visnyk ODABA. No. 62. Pp. 111-116.

5. Voznesenskii V.A., Liashenko T.V., Ivanov Ia.P. and Nikolov I.I. (1989). EVM i optimizatsiia kompozitsionnykh materialov. Kyiv: Budivelnyk. 240 p.

\section{INCREASING EFFICIENCY OF WATERPROOFING SCREENS WITHIN THE CONCEPT OF CONSERVATION OF CULTURAL HERITAGE OBJECTS}

\begin{abstract}
The article discusses the causes of the violation of the waterproofing of the underground parts of buildings which are made of limestone-shell rock. Unflod the problems of preserving historic buildings and structures from limestone-shell rock in Ukraine and Moldova, such as the Odessa Opera and Ballet Theater, the Strats House, the Brodsky Synagogue, the Marazli House, the Belgorod-Dniester and Bender Fortresses, the Tower of the Winds, the Church of St. Kaetan, the Powder Cellar of Tiraspol Fortress, are revealed, Water Mill, Church of the Archangel Michael in with. Stroentsy and many others. The expediency substantiated the conducting studies of the effectiveness of injection technology in the installation of waterproofing screens, depending on the following factors: the depth of injection (X1); borehole diameter (X2); injection steps (X3) with a range of variation of X1 - 14, 16 and $18 \mathrm{~cm}, X 2-8,12$ and $16 \mathrm{~mm}, X 3-10.15$ and $20 \mathrm{~cm}$.

Based on the methods of the mathematical theory of the experiment, a complex of experimental-statistical models has been constructed, the analysis of which allowed us to estimate the intensity of capillary absorption of the "waterproofing screen - limestone-shell rock" system depending on the depth of injection, the diameter of the injector and the step of its location.

An arrangement of injection holes was proposed and justified to ensure waterproofing of structures, which allows filling the capillary-porous masonry space for 6-12\% more than other schemes. The accepted physical model of the distribution of the injectable composition in the porous structure of limestone-shell rock allowed us to analyze the depth, diameter, and injection step, which affect the distribution area of the solution in the structural array. The depth of injection is indeed one of the most important technological characteristics in the construction of an intra-structural waterproofing screen. From a technological point of view, the degree of influence of the injection step on the intensity of capillary moisture transfer is quite high, since it directly affects the amount of active waterproofing composition in the injected thickness, as well as labor costs when performing waterproofing works. The diameter of the borehole does not significantly affect the studied parameter within the selected experimental conditions.
\end{abstract}

Key words: limestone-shell rock, injection waterproofing, waterproofing screen, capillary absorption, mathematical modeling.

\section{Dmytriieva N.V.}

Candidate of Technical Sciences, Associate Professor,

Odessa State Academy of Civil Engineering and Architecture, Odesa

\section{Trofimova L.E.}

Candidate of Technical Sciences, Associate Professor,

Odessa State Academy of Civil Engineering and Architecture, Odesa

Kyryliuk S.V.

Candidate of Technical Sciences, Head of Laboratory,

Odessa State Academy of Civil Engineering and Architecture, Odesa

Shamshur A.P.

Lecturer, Head of Laboratory,

Bendery Polytechnic Branch of the Taras Shevchenko Transnistria State University, Moldova 